\title{
Hospital acquired Methicillin Resistant \\ Staphylococcus aureus (MRSA) in Angelina County, Texas
}

Authors:

Anuoluwapo Adelodun, Abdulaziz Bako, Lucia Ejoh, Chandni Patel, Tijjani Sani, Robin Sheoran 
Section 1: Identification of Health Problem and its Mechanism, and identification of Organizational Context

Healthcare-associated infections (HAls) are infections patients are prone to while receiving medical treatment in a healthcare facility and can be defined as 'healthcareassociated' if they develop 48 hours after admission, receiving medical care or within 30 days of having a surgical procedure (Nelson \& William 2013). HAls occur in all settings of care and across the continuum of care, including hospital acute care units, day procedure centers, ambulatory outpatient clinics, dialysis centers, long-term care facilities, nursing homes, and rehabilitation centers (Welsh, Flanagan, Hoke, Doebbeling, \& Herwaldt, 2012).

Risk factors for HAls include host factors such as compromised immune system due to underlying disease or disruption of mucosal and skin surfaces that increases their risk of developing infections or acquiring organisms that are either high or low virulence. The hospital environment also facilitates the spread of microbial pathogens due to patient proximity, contamination of common equipment, and exposure to water contaminated with microorganisms. Interestingly, new healthcare technologies and methods of monitoring and caring for patients create new portals of entry for infection alter normal host flora, thereby increasing the risk of HAls (Burke, 2003).

In the United States, the Centers for Disease Control and Prevention (CDC) estimates that nearly 2 million patients experience an HAl each year. This means that 1 in every 10-20 hospitalized patients in the country develops such an infection. These infections cause almost 100,000 deaths and are responsible for an extra $\$ 4.5$ billion to $\$ 6.5$ billion in healthcare expenses (Zimlichman et al., 2013).

Bacteria cause approximately $90 \%$ of HAls, with viruses, fungi, protozoa, and other classes of microorganisms causing the remaining 10\% of infections (Goto \& Al-Hasan, 2013). The most common pathogens isolated in HAls are coagulase-negative staphylococci (CoNS, 15.3\%), Staphylococcus aureus (14.5\%), Enterococcus species (12.1\%), Escherichia coli (9.6\%), and Pseudomonas aeruginosa (7.9\%). MRSA (Methicillin-Resistant Staphylococcus Aureus) is a class of bacteria that are resistant to beta-lactam antibiotics, such as methicillin, penicillin, oxacillin, and amoxicillin. MRSA may be incurable leading to severe infections and death (MRSA, 
2015). As of 2003, 64 percent of staph infections were caused by MRSA. The Center for Disease Control and Prevention (CDC) identified MRSA as the leading cause of HAl in present times, estimating about 81,000 invasive MRSA infections and 12,000 related deaths occurring as of 2011 (CDC, 2013). It has been a universal cause of morbidity and mortality.

The Health Care Agency (HCA) being role-played is the Angelina County Health Department whose vision and mission are to protect and promote the health and safety of individual residents, families, and communities in Angelina County. Angelina County, with a population of over 3 million individuals, is a fairly heterogeneous population with an eclectic ethno-racial makeup dominated by whites and blacks and Hispanic racial and ethnic groups (State and county quickfacts, n.d). In Angelina County, Texas, MRSA is responsible for single hospital outbreaks with rapid spread within the hospital. In addition, other regional hospitals may be affected since they share patients (Lee et al., 2011).

\section{Section 2: Descriptive Epidemiology of the Problem}

The incidence of hospital associated MRSA (HA-MRSA) is decreasing in many states across the US, including Texas (CDC, 2015). In the year 2013, there were 0.87 MRSA infections per 1,000 populations, which is below the National average of 0.92 per 1,000 population (CDC, 2015). However, in 2014, the incidence of MRSA in Texas started rising, and MRSA became the most frequently reported multidrug resistant organism in the state (Vinyard, 2015). Lack of data that classifies the reported incidence on the basis of whether the infection is hospital associated or community associated makes it difficult to ascertain which of the two types is responsible for the rise.

Angelina County, with a projected MRSA infection incidence rate of 578 per 100,000 populations in 2011, has one of the highest projected incidences of MRSA in the state of Texas (surpassing the projected incidence rates of Bexar, Brazos and Potter/Randall counties) (DSHS, 2015). Majority of the infected persons reported a history of hospital admission within the last 12 months (DSHS, 2015). Majority of those infected are white, and elderly persons greater than 70 years (DSHS, 2015).

In 2012, the CDC implemented the Active Bacterial Core Surveillance (ABCs) which was a report defining the trends of MRSA in nine different states. There are three major epidemiological 
classifications of MRSA based on its method of acquisition. Cases in which the MRSA culture was obtained on or before the fourth calendar day of hospitalization (where the day of admission is defined as hospital day 1) are classified as healthcare-associated community onset (HACO) MRSA. Patients who fall into the HACO category but with a previous history of surgery, dialysis or hospitalization in the previous one year or who had a central venous catheter placed within 2 days preceding the MRSA culture are classified as hospital acquired (HA) MRSA. All those who do not fall into either category are classified as community-associated (CA) MRSA (CDC, 2014).

The overall incidence rate of invasive MRSA infections in the United States in 2012 was 23.99 (95\% Cl: 20.64-28.10). Middle age and elderly people had the highest incidence rates especially of HACO (CDC, 2014). Hemodialysis accounted for $95.7 \%$ of dialysis-associated MRSA in the HA-MRSA category. The overall mortality rate of MRSA in 2012 was 3.08 (95\% Cl: 2.15-4.48). Although the incidence of HACO-MRSA in 2012 (18.74) decreased by 30.8\% compared to 2008 (27.08), it is still a significant cause of morbidity and mortality in the healthcare setting (CDC, 2014). Diligent efforts are required to formulate prompt interventions that will completely eradicate MRSA in Angelina County and in the United States.

In March 2011, The Texas Association of Local Health Officials (TALHO) carried out a pilot program in collaboration with the Department of State Health Services (DSHS, 2015). Three local health departments were recruited in the study namely: 1. Angelina County and Cities Health District; 2 . WacoMcLennan County Public Health District; and 3. Fort Bend County Health and Human Services.

Demographics, MRSA cultures and risk factor information were collected. Positive cultures from clinics and laboratories were obtained and interviews were conducted where possible. The results from the study were rather interesting and lead to the choice of this location for an intervention.

A total of 40 persons with methicillin-resistant Staphylococcus aureus (MRSA) infections were reported in Angelina County with a projected annual incidence rate of 578 cases per 100,000 population (DSHS, 2015). This incidence rate was higher compared to the projected incidence rates in Bexar, Brazos and Potter/Randall counties as reported by a previous study in the region. Also, this rate is higher than the national average and a careful extrapolation estimates the total number of MRSA infections across Texas to be around 144,000 .

A closer look at the study revealed that the number of MRSA infections in Angelina County were likely greater than the 40 reported cases. Data was obtained from the clinical reference laboratories in Angelina County, and people who had medical providers outside the county were not reported in the 
study. The culture reports from the laboratories lacked pertinent patient information like addresses and phone numbers, which made follow up difficult.

The local health authorities in Angelina County are severely paralyzed in their efforts to handle the situation due to lack of funds and resources. The 2011 report also suggested that MRSA was intentionally left out of the reportable disease list as including it would have created difficulties for the departments concerned, since they were not capable of handling such a challenge at the time. This is quite alarming for a disease, which is estimated to affect 144,000 people across the state.

Furthermore, the distribution of MRSA cuts across a wide range of age groups, ranging from 2 months to 99 years and males are more commonly affected (around 55\%). The mean age was found to be around 55 years with many above 70 years. A vast majority of those affected were whites (87\%) and the rest were African-American (13\%). 31\% of the white population were Hispanics.

Most of the people infected (69\%) had some kind of wound, skin or soft tissue infection. Wounds and abscesses (21\%) were the most frequent sites for specimen collection, followed by respiratory tract (18\%), urine (15\%) and, blood (3\%) as these was the most common site found for MRSA infection (DSHS, 2015).

A history of hospitalization in the past 12 months was reported as a risk factor in a majority (58\%) of cases. Of the 40 reported cases, nine were reported to have undergone some kind of surgery in the past 12 months within the county, while five of them had undergone extended periods of stay in a long-term facility.

In other studies, immunocompromised patients were shown to be at particularly high risk of developing MRSA $(2=4.92, p=0.026)$ (Eseonu et al.,2011). Approximately half of the nosocomial MRSA infections occur in critical care settings (Wisplinghoff et al., 2011), although only a small number of patients receive treatment there. The high rates of antibiotic resistance, local patterns of MRSA, as well as antibiotic susceptibility in certain population groups should direct further efforts on the issue. Critical care units; long-term facilities and surgical units catering to the elderly population are prime targets for intervention.

\section{Section 3: Analytical Epidemiology}

As earlier discussed, MRSA infection is classically known to be associated with healthcare settings and risk factors such as recent admission as well as use of catheters and intravenous lines, living in nursing homes and dialysis have been associated with the infection (Wooten \& Winston, 2013). Additionally, in long-term care facilities, MRSA is able to spread from one patient to another though 
healthcare workers. Hands/gloves can become contaminated with MRSA when healthcare workers touch a patient's skin, wounds (dressings), or IV tubing (Harris, 2015).

Since the mid-1990s however, there has been an explosion in the number of MRSA infections reported for populations without a risk factor of exposure to a healthcare setting. This increase has been associated with the recognition of new MRSA strains, often called community-associated MRSA (CAMRSA) that have been responsible for a large proportion of the increased disease burden observed in the last decade (David \& Duam, 2012).

People who develop CA-MRSA are more likely susceptible if they have tattoos, body piercings, and skin trauma, shave or wax to remove body hair. Those who share personal items or equipment that are not cleaned between users, have physical contact with a person who has a cut or sore or is a carrier of MRSA, or who are athletes are also at great risk (Harris, 2015). These strains appear to have spread rapidly among the general population in most areas of the United States and affect patients with and without exposure to the health care environment. Studies have shown that patients who upon admission, test positive to MRSA colonization from CA-MRSA are about 12 (95\% Cl: 8.0-17.5) times more likely to develop HA-MRSA infection than patients without initial CA-MRSA colonization (Reilly et al., 2012).

An important issue is determining the origin of MRSA infection. Exposure to the health care environment does not preclude acquisition in the community of USA300 or other MRSA strains from another healthy individual. New high-risk groups may represent populations at risk unrelated to health care environment exposure, including incarcerated populations, athletes, children, inner-city residents, and Native Americans (Magill et al., 2014).

Nasal or mucocutaneous colonization with MRSA is identified as a potential reservoir for infection in the individual patient as well as transmission to other patients and healthcare workers in several studies (Jafarzadeh et al., 2014). However, other findings suggest that nasal carriage may not be the main acquisition pathway for surgical site infection (SSIs). In these studies though, nasal carriage was a risk factor for $\mathrm{S}$. aureus SSI, but the majority of infections occurred in non-carriers or were associated with a strain that was different from the one obtained at screening (Zacharioudakis et al., 2014). In contrast, another researcher reported that nasal screening with decolonisation reduced the number of surgical wound infections due to methicillin-susceptible S. aureus (MSSA) (Bode et al., 2010).

Nasal screening gives the highest yield for detection of MRSA carriage but screening only the nares may fail to identify those patients who are colonized at other body sites and who can still transmit the organism to others (Harbarth et al., 2011). Other unresolved issues include whether screening 
should be universal or targeted, and the most suitable testing method for screening and diagnosis. There is low strength of evidence that universal screening lowers MRSA infection as available literature consists mainly of observational studies with insufficient control for secular trends and confounders (Harbarth et al., 2011).

Systematic review of isolation policies in the hospital management of MRSA in the UK has shown that isolation can substantially reduce MRSA, even in settings with a high level of endemic MRSA (Cooper et al., 2003). However, the predominance of unplanned retrospective reports suggests that reporting bias may be present and robust economic evaluation was lacking.

\section{Section 4: Social Ecological Analysis}

A systematic literature review was performed utilizing Texas A\&M University Libraries Medical Sciences Library search engine to identify peer-reviewed articles on successful interventions targeting MRSA as a hospital-acquired infection. To decide which socio-ecological level to focus on, three levels of interventions were considered: personal, community, and organizational. The two search engines used were Google Scholar and PubMed, and the range of the search for relevant articles was between the years 2011 and 2015.

The search for interventions on the personal level using the Google Scholar database yielded 3,530 results from which three articles were selected and the keywords used were: MRSA, individual level interventions. The articles selected were Hefzy, Wegdan, and Wahed (2015), Duerink et al. (2006), and Talbot et al. (2013). Furthermore, for the community level interventions, the search from Google Scholar generated 9,750 results using keywords: MRSA, community interventions. The three articles that were selected were Golding, et al. (2012), Jenkins, et al. (2012), and Skov, et al. (2011). Lastly, for the organizational level, eight articles were generated on PubMed using the search terms: MRSA, organizational level, interventions. The interventions selected were Flodgren et al. (2011), Henderson et al. (2012), and Mestre et al. (2012).

In comparison with other levels of intervention, the organizational level intervention was chosen because of its popularity and effectiveness in the reduction of MRSA infections (Gould, 2013). Although, an overlap was identified between the personal and organizational levels, many successful interventions were found at both levels. 


\section{Section 5: Description of previous level-Specific methods and proposed methods}

The study conducted by Hefzy et al. (2015) aimed to assess the potential hazard posed by hospital outpatient clinics for hospital-acquired infections. The study was divided into two parts; the

first being a descriptive cross-sectional part assessing the health care personnel's knowledge and compliance with standard precautions. The second consisted of an intervention to assess the role of education in reducing the environmental and bacterial contamination of reusable healthcare equipment. Following the intervention, a significant reduction in indicator organism was noted $(p=0.00)$. Prevalence of MRSA dropped from $38.9 \%$ to $16.7 \%$. The differences are significant and clearly show the effectiveness of personal level interventions in reducing healthcare induced infections.

In a study conducted by Talbot et al. (2013), multimodal strategies were instituted. These strategies included: system leadership buy-in, hand hygiene education campaigns, utilization of covert observers to monitor hand hygiene practices, and provision of financial incentives to high performers. A statistically significant improvement in hand hygiene compliance $(p<0.001)$ was observed, and this improvement in compliance was inversely correlated with device associated infection ratios $\left(R^{2}=0.70\right)$ (Talbot et al., 2013).

In a study conducted by Duerink et al. (2006), education campaign on hand hygiene was instituted. This was followed by observation of health workers (by covert observers) while practicing hand hygiene and providing them with feedback on their performance. Staffs that are practicing standard hand hygiene were given some financial incentive to reinforce their behavior. At the conclusion of the study, these interventions were found to significantly improve and sustain hand hygiene compliance from $46 \%$ to $77 \%$ in Internal Medicine and from $22 \%$ to $62 \%$ in Pediatrics (Duerink et al., 2006).

Evidence from multiple literatures suggests that application of a single intervention is usually not successful in improving hand hygiene adherence (Crews et al., 2015; Luangasanatip et al., 2015). Multimodal strategies that involve the use of education, feedback, reminders, incentives, and goal setting are more effective in improving adherence to standard hand hygiene practices (Crews et al., 2015; Luangasanatip et al., 2015).

This project aims to utilize the Transtheoretical Model (TTM) developed by Prochaska and DiClemente (1982) for its interventions. According to this model, the process of change, among other things, involve raising awareness on a healthy behavior and stimulating emotional arousal (positive or negative) that will cause dramatic relief in the subjects. One of the interventions in this project, education and training of 100 health workers, seeks to raise awareness of health workers on standard 
hand hygiene practices and negative consequences of poor hand hygiene practices. Part of the training will involve training of healthcare workers on how to observe their colleagues covertly while performing hand hygiene. Observers will be assigned per shift to monitor, score, and record hand hygiene practices among their colleagues. Observer ship status will be assigned randomly per shift excluding those that were assigned previously until all staff has been exhausted.

The Integrated Theory of Health Behavior Change suggests that provision of feedback to subjects on their performance improves their ability to maintain healthy behavioral change (Ryan, 2009). Therefore, Feedback on performance level of all staff will be provided individually, and where necessary, corrective advice will be given to extreme underperformers. Other processes of change suggested by Prochaska and DiClemente (1982) in the TTM are stimulus control using cues and reminders that support healthy behavior and reinforcement of good behaviors by providing reward for such behaviors. Thus, Reminders on standard hand hygiene practices will be posted in all notice boards and offices of the hospital. Prices and special recognition will be given to the top 5 performing staffs at the end of the project.

\section{Section 6: Logic Model and Timeline}

\begin{tabular}{|c|c|c|c|c|c|c|c|c|c|c|c|c|c|c|c|c|}
\hline TASKS & MONT & & & & & & & & & & & & & & & \\
\hline & January & February & March & April & May & June & July & August & September & October & November & December & January & February & March & April \\
\hline Staff Hiring & & & & & & & & & & & & & & & & \\
\hline $\begin{array}{c}\text { Staff } \\
\text { Training }\end{array}$ & & & & & & & & & & & & & & & & \\
\hline $\begin{array}{l}\text { Baseline } \\
\text { Surveys }\end{array}$ & & & & & & & & & & & & & & & & \\
\hline $\begin{array}{l}\text { Stakeholder } \\
\text { Meetings }\end{array}$ & & & & & & & & & & & & & & & & \\
\hline $\begin{array}{l}\text { Design } \\
\text { Program }\end{array}$ & & & & & & & & & & & & & & & & \\
\hline $\begin{array}{l}\text { Health } \\
\text { Education } \\
\text { Classes }\end{array}$ & & & & & & & & & & & & & & & & \\
\hline Evaluation & & & & & & & & & & & & & & & & \\
\hline $\begin{array}{c}\text { Data } \\
\text { Analysis }\end{array}$ & & & & & & & & & & & & & & & & \\
\hline $\begin{array}{c}\text { Program } \\
\text { Results/ } \\
\text { Presentation }\end{array}$ & & & & & & & & & & & & & & & & \\
\hline
\end{tabular}




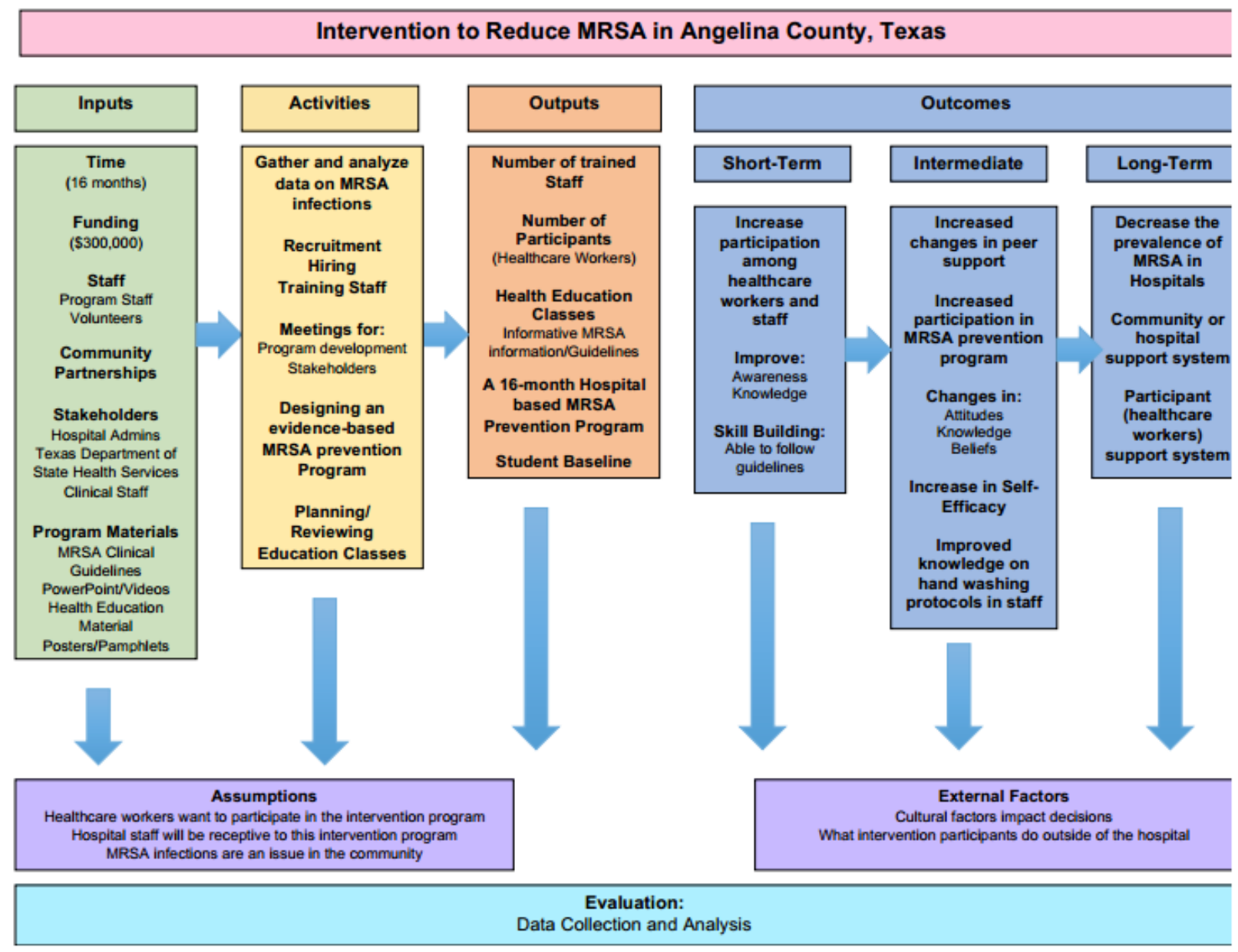

\section{Section 7: Evaluation Plan}

Process Evaluation will be used to document and monitor program implementation and it will help aid the understanding of specific relationships between program elements and program outcomes. The process evaluation will use frameworks and logic model components as guidance for the evaluation plan. Additionally, the process evaluation will cover process measures, methodological issues, and an implementation plan for it to successful.

The elements to be examined in the evaluation plan for this project include: progress in the process of implementing the intervention; knowledge, attitude; and practice of standard hand hygiene practices among hospital staff; rate of compliance with standard hand hygiene practices; and the incidence of MRSA in both intervention and control facility. Quantitative evaluation of process and outcome measures at baseline and post intervention will be conducted, including: standard hand hygiene compliance rates and MRSA infection rates. 
The study design for this intervention will be quasi experimental in which two hospitals, matched by MRSA infection rate and patient case mix, will be selected. One of the hospitals will receive the intervention package while the second hospital serves as control.

The logic model components include: inputs, activities, outputs, and outcomes (short-term, intermediate, and long-term). Data collection for the inputs, the resources that go into the program begins with time, funding, staff, stakeholders, and program materials. Data collection for the activities, the actual events or actions that take place begins with recruitment, hiring, and training staff, meetings, designing programs, planning classes and using baseline surveys. Data collection for the outputs, activities, services, events and products that reach people who participate begins with number of staff trained, number of total participants, health education classes, prevention program, and student baseline measurements. Lastly, data collection for the outcomes of the program includes the sequence of effects triggered by the program (often expressed in terms of short-term, intermediate, and longterm) will be as follows:

- Short-term outcome measures: change in knowledge and attitude towards standard hand hygiene practices among trained staff

- Intermediate outcome measures: rate of compliance with hand hygiene practices

- Long-term outcome measures: Change in the rate of MRSA infection.

The cleanliness champions for this project will be selected from nurses, doctors, and physician assistants. This selection will be based on rank and availability of the staff during routine activities. Each trainee will be offered some fund to organize training to his colleagues on hand hygiene practices.

The sample to be evaluated will include all clinical staff (doctors, nurses, and physician assistants) in two major hospitals in Angelina County.

Regression analysis will be conducted to determine the predictors of practice of hand hygiene practices among intervention and control group.

\section{Section 8: Management Overview}

The project will be handled by a team of experienced personnel in various positions that will include: a Project Coordinator, an Assistant Project Coordinator, Chief Administrator, Health Educator, Program Evaluator, other project staff, and volunteers. The Project Coordinator will oversee the entire program, the Assistant Project Coordinator will oversee the minor yet crucial aspects of the program, such as coordination of the surveys as the means of data collection, supervision of the health education classes with the Health Educator, etc. The Chief Administrator will be responsible for administrative 
activities, such as staffing, budgeting, and financing. The Health educator will oversee the health education classes related to the intervention and this would include taking charge of the healthcare workers education sessions, implementing the use of proper hand washing skills, the communicative use of posters, fliers, and voiceovers throughout the hospital and spreading knowledge throughout the community. Volunteers will be tasked with gathering health education materials and resources, and passing them out to the hospital community.

Health education materials will be adopted from Centers for Disease Control (CDC)'s resources such as hand washing videos, brochures and guidelines on Hospital Acquired Infection, and hand washing training (Centers for Disease Control and Prevention, 2014). The Woodland Heights Medical Center's Hospital Infection Prevention and Control team would provide the baseline data on incidence of MRSA in the hospitals and would also help in identifying and acquiring community-wide partners that will participate or collaborate in the activities of the program, as well as in meetings. The Woodland Heights Medical Center would provide a venue for the task force meetings and the final presentation of the project findings.

For development and promotion of educational materials around the hospital, the use of fliers and posters, broadcasting videos on television/computer screens around the hospital and patient rooms, use of 30-second voiceovers over the intercom to remind staff about proper hand hygiene would be employed.

At the end of the program, a final presentation of detailed project findings will be given during the last month. Community members, including the City Council, Board of health, and representatives from the Texas Infectious Disease Society will be invited for the final presentation. Also, additional reports will be handed out to participants in the final presentation, local hospitals, community members, and the media.

Funding resources will be used for providing education materials to staff, broadcasting purposes (short videos, voiceovers, posters, etc.), and reward schemes will be implemented for employees who practice regular hand washing. 


\section{Timeline of milestones:}

\begin{tabular}{|c|c|}
\hline Month & Activity \\
\hline $\begin{array}{l}\text { January- } \\
\text { February (First } \\
\text { year) }\end{array}$ & $\begin{array}{l}\text { Intervention Program begins. Project Coordinator and Project Administrator will } \\
\text { conduct the hiring and training of staff within this time }\end{array}$ \\
\hline $\begin{array}{l}\text { March (First } \\
\text { year) }\end{array}$ & $\begin{array}{l}\text { Stakeholders meeting will hold. In this time as well, the Project Coordinator and Staff } \\
\text { will design a curriculum for the health education classes, map out ideal places to } \\
\text { display educational materials such as posters, and review video and voiceover } \\
\text { scripts. } \\
\text { Baseline survey begins. }\end{array}$ \\
\hline $\begin{array}{l}\text { April (First } \\
\text { Year) }\end{array}$ & Baseline survey ends \\
\hline $\begin{array}{l}\text { May - August } \\
\text { (First year) }\end{array}$ & A series of health education classes will be held for four consecutive months \\
\hline $\begin{array}{l}\text { March- April } \\
\text { (Second year) }\end{array}$ & $\begin{array}{l}\text { Final presentation and results of the intervention will be shared with the city council } \\
\text { members, local hospitals, and community members during this time. The } \\
\text { intervention program ends }\end{array}$ \\
\hline
\end{tabular}

*Evaluation and data analysis will be held every month during the entire intervention program.

Based on the Quasi-experimental study design proposed for the evaluation phase of the intervention, a baseline measure of the prevalence of MRSA infections in the hospitals being studied would be carried out to determine known levels of infection to which to compare future measures. The second hospital will be selected as a control and no interventions would be carried out in that hospital. Cases and controls will be matched based on demographics and other characteristics and then randomly assigned to groups to measure post intervention rates of MRSA. This study design is known to yield important evidence concerning the efficacy of an intervention (Derde et al., 2014). 
Seeing that the hand hygiene intervention is not so much a problem of funding or lack of support from external sources, the most common challenge envisaged would be the attitude of the staff as adoption of the new culture is always a possible source of a problem (Saint, Krein, \& Stock, 2014). Studies have shown that the more non-tolerant the management is of non-compliance, the wearier staff becomes thereby reducing morale to work. Therefore, Management would need to find a more 'friendly' method to execute the proposed intervention (Borg, Waisfisz, \& Frank, 2015).

In the execution phase of this study, observers will be assigned to each cadre of staff in the study who will be monitoring compliance with hand hygiene practices. Feedback on the level of performance will be provided to individual staff and a special recognition will be given to the most compliant cadre of staff all in an effort to improve compliance. In the presence of glaring evidence that the intervention is working, the hospital management will incorporate these hand hygiene practices into its management protocols and standards of practice and also continue to recognize compliance champions in order to reinforce the practice among all staff.

\section{Section 9: Limitations of proposal, anticipated challenges, and policy implications/strategies to resolve those challenges}

Interventions that involve behavior modifications and change are generally difficult to implement and monitor as non-performance bias is always an issue given the complexity of the response (Saint, Krein, \& Stock, 2014). In order to ensure adherence to the hand washing and hygiene protocols, timely reminders to the staff is required. This becomes all the more difficult in a hospital setting that is known to face frequently staff shortages and rapid staff turnovers. Poor retention rates for the staff have been mainly attributed to lack of organizational commitment and professional satisfaction (Lynn 2003). The study design chosen allowed comparison between two hospitals, however controlling for some confounders, that are enablers and barriers to $\mathrm{HH}$ behavior may be difficult. Some of these enablers and barriers include how the health workers perceived the risk to themselves based on the type of clinical activity to be carried out, how clean they deemed the patient to be, and the general workload.

Education alone has shown to produce mixed results in the past, and therefore a multimodal, multidisciplinary effort is required. Barriers to Hand hygiene compliance include understaffing, poor design of facilities, confusing and impractical guidelines and policies, failure to apply behavioral change theory fully and insufficient commitment and enforcement by infection prevention and control personnel (Burke 2003). Installation of video cameras at hand washing stations could increase 
compliance. Efforts should be made towards improving the design of the facility in order to increase access to the hand washing stations for the staff. The guidelines and policies governing infection prevention and control need to be clearly defined in view of the current literature findings.

To evaluate the impact of our intervention, one of our outcomes will measure the number of essential hand washes performed after activities by health workers. However, the possibility of a Hawthorne Effect; increased productivity i.e. more hand hygiene episodes resulting from the presence of observers (Sedgwick, 2012) exists and as such the identity of the monitors will remain undisclosed to the health care workers. In addition, we intend to use of liters of alcohol-based hand rub consumed as an indirect measure of the hand hygiene activity to complement direct observation.

The effectiveness of the hand hygiene in reducing MRSA in the hospital setting is based, at least in theory, on preventing the transfer of bacteria from the Health Care Worker's hand to the patient thereby interrupting the chance for cross infection. Microbiological sampling of hands to determine whether hand hygiene actually reduced bacterial counts is the most appropriate to measure effectiveness of hand hygiene (Derde et al., 2014). However, we could not carry this out because of financial constraints. We therefore intend to use the difference in the rate of MRSA infections between the intervention and control centers to measure this and the results should show a gradual decrease in MRSA incidents compared to the control centers.

\section{Policy Implications}

The pragmatic approach of screening every new admit to the hospital before being admitted could help reduce the MRSA infection spread. The principles of hand hygiene along with other recommended high standards of environmental cleaning and decontamination should help in this regard. These recommendations should conform to the changing requirements and knowledge of the research in the area. The studies up until now have been plagued by major methodological weaknesses and inadequate reporting, leading to many plausible alternative explanations for MRSA reduction associated with interventions cannot be excluded. The findings from the report can be used to make recommendations for better design for future studies and help in the production of transparent reporting of Outbreak Reports and Intervention studies Of Nosocomial Infections, commonly known as ORION. ORION is currently a work in progress and requires ongoing dialogue for successful promotion and dissemination. In addition to improving the transparency of reporting, the ORION guidelines seek to help readers to relate studies to their situation, facilitate synthesis of evidence, and to provide a framework for reviewers and editors to assess papers and research grant applications (Stone 2007). 
ORION can also be extremely helpful in planning study design, and identification of potential confounders that may otherwise affect the internal validity of the study.

\section{Section 10: Proposed Budget and Budget Justification}

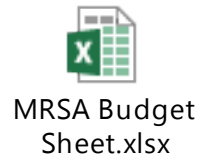

\section{Personnel Services (PS)}

\section{A. Salary}

Total: $\$ 167,795$

Project Coordinator: The Project Director, Dr. Adam (PhD), will spend 40\% of his time in the first year and 2nd year to oversee the planning and implementation of this program. Dr. Adam's Full Time Equivalent (FTE) salary is $\$ 75,000$. Based on this $\mathrm{FTE}$, his annual salary will be $\$ 30,900$ in the first year and $\$ 31,827$ in the second year, totaling $\$ 62,727$ for the entire project.

Assistant Project Coordinator: The Assistant Project Coordinator, Mrs. Murray (MSc.), who works at the hospital will devote $50 \%$ of her time in both the first and 2 nd year assisting the project coordinator with the implementation of the program. Mrs. Murray's Full Time Equivalent (FTE) salary is $\$ 45,000$. Based on her FTE, the annual salary of Mrs. Murray was calculated to be $\$ 23,175$ for the first year and $\$ 23,870$ for the second year, totaling $\$ 47,045$ for the entire project.

Administrative assistant: The Administrative Assistant, Mr. Anand (MA) will devote $30 \%$ of his time providing office services by implementing administrative procedures and policies. Mr. Anand's Full Time Equivalent (FTE) salary is $\$ 40,000$. Based on his FTE, Mr. Anand's annual salary will be $\$ 12,360$ in the first year and $\$ 12,731$ in the second year, totaling $\$ 25,091$ for the entire project.

Health Education Specialist: The Health Education Specialist, Ms. Audrey (M.Sc), will devote 35\% of her time offering health education classes and designing other education and communication materials for the project. Her Full Time Equivalent (FTE) salary is $\$ 45,000$. Based on her FTE, Ms. Audrey's annual salary will be $\$ 16,223$ in the first year and $\$ 16,709$ in the second year, totaling $\$ 32,932$ for the entire project.

\section{B. Fringes}

Total: $\$ 53,874$

The Fringe benefits for the Project Coordinator, Assistant Project Coordinator, Administrative Assistant, and Health Education Specialist are $26.1 \%, 34.4 \%, 36.6 \%$, and $34.4 \%$, respectively, of their annual 
salaries for the project. The total fringe benefits for these employees are $\$ 26,730$ for the first year and $\$ 27,114$ for the second year, totaling $\$ 53,874$.

\section{Graduate Student}

Total: \$21,586

A graduate student will be hired, and will spend $50 \%$ of his/her time assisting with data collection and analysis in this project. The Full Time Equivalent (FTE) salary of a graduate student is $\$ 15,000$. Based on this FTE, the graduate student's annual salary will be $\$ 7,725$ in the first year and $\$ 7,957$ in the second year, totaling $\$ 15,682$ for the entire project. The fringe benefits for the graduate student will be $37.6 \%$ of his annual salary, thus totaling $\$ 5,904$ for the whole project. The total salary and fringe benefit of the graduate student would therefore be $\$ 21,586$.

\section{Other Than Personnel Services (OTPS)}

A. Materials/Supplies

Total: $\$ 3,410$

Office supplies: office supplies, including folders, pens, dry erase markers, flip charts, and black permanent markers will be purchased at the cost of $\$ 510$.

Meeting supplies: Refreshment will be provided during each training session, which will be conducted twice a week for 8 weeks, making a total of 16 sessions. \$100 will be spent on refreshment in each session, making a total of $\$ 1,600$ for all the 16 sessions.

Also, results of this project will be formally presented to the participants of the program, staff of our organization and the stakeholders at a local community center provided by the Angelina county city council. Food and refreshments will be provided for those in attendance. The total cost for the presentation will amount to $\$ 1,500$.

\section{B. Printing and Audition}

Total: $\$ 900$

Voice over recording: A professional audition of a 3-minute audio voice over message will be procured at the cost of $\$ 500$

Manuals: 150 copies of a 12 page training manual will be printed at the cost of $\$ 200$ by Office Depot printing services.

Executive Summary: We will document the findings of this project into a 1 page executive summary. We will print and disseminate 100 copies of the executive summary at the cost of $\$ 1$ per copy, for a total of $\$ 100$ for 100 copies. 
Comprehensive Report: We will print 20 copies of a comprehensive report of this project, and distribute it to our partners and collaborators at the cost of $\$ 5$ per copy, for a total of $\$ 100$ for 20 copies.

\section{Travel cost}

Total: $\$ 800$

The assistant project coordinator and the health education specialist will be given $\$ 300$ worth of gas card each, while the project coordinator will be given a $\$ 200$ worth of gas card because majority of the travel will be done by the assistant project coordinator. This makes a total of $\$ 800$ for gas cards.

\section{Participant incentives}

Total: $\$ 10,000$

Each of the 100 training participants will be given $\$ 100$ gift card as an incentive after participation in the training, making it total of $\$ 10,000$ for the 100 participants.

\section{E. Prices to best performing staff}

Total: $\$ \mathbf{2 , 3 0 0}$

Gift cards will be given to the best performing staff in the following order. $\$ 1,000$ for the best performing staff, $\$ 500$ to the second best, $\$ 300$ for the third, and $\$ 250$ each for the 4 th and 5 th positions.

\section{Administrative Overhead Costs (15\%):}

Total: $\$ 39,099$

Our agency charges $15 \%$ of the total cost as an administrative overhead cost. This makes the overhead cost for the first year to be $\$ 20,619$, and that for the second year to be $\$ 18,480$. The total overhead cost is, therefore, $\$ 39,099$.

\section{TOTAL COST OF PROJECT: \$299,764}




\section{References}

Bode, L. G. M., Kluytmans, J. A. J. W., Wertheim, H. F. L., Bogaers, D., Vandenbroucke-Grauls, Roosendaal, R.,Vos, M. C. (2010). Preventing surgical-site infections in nasal carriers of staphylococcus aureus. N Engl J Med, 362(1), 9-17. doi:10.1056/NEJMoa0808939

Borg, M., Waisfisz, B., \& Frank, U. (2015). Quantitative assessment of organizational culture within hospitals and its relevance to infection prevention and control strategies. Journal of Hospital Infection, 90(1), 75-77.

Burke, J. P. (2003). Infection control - A problem for patient safety. N Engl J Med, 348(7), 651-656. doi:10.1056/NEJMhpr020557

Centers for Disease Control and Prevention. (2012). Active Bacterial Core Surveillance Report, Emerging Infections Program Network, Methicillin - Resistant Staphylococcus aureus, 2012. Retrieved from CDC website. http://www.cdc.gov/abcs/reports-findings/survreports/mrsa12.pdf

Center for Disease Control and Prevention (2013) Antibiotic Resistance Threats in the United States 2013 US Department of Health and Human Services, Atlanta, Georgia (2013) (Retrieved from http://www.cdc.gov/drugresistance/threat-report-2013/)

Centers for Disease Control and Prevention (CDC). (2015). National and state healthcare associated infections progress report, March 2015. Retrieved from CDC website. http://www.cdc.gov/HAl/pdfs/progress-report/hai-progress-report.pdf

Cooper BS, Stone SP, Kibbler CC, et al. Systematic review of isolation policies in the hospital management of methicillin-resistant Staphylococcus aureus: a review of the literature with epidemiological and economic modelling. 2003. In: NIHR Health Technology Assessment programme: Executive Summaries. Southampton (UK): NIHR Journals Library; 2003. Available from: http://www.ncbi.nlm.nih.gov/books/NBK62321/

Crews, J. D., Whaley, E., Syblik, D., \& Starke, J. (2013). Sustained Improvement in Hand Hygiene at a Children's Hospital. Infection Control,34(07), 751-753.

David, M. Z., \& Daum, R. S. (2010). Community-Associated Methicillin-Resistant Staphylococcus aureus: Epidemiology and Clinical Consequences of an Emerging Epidemic. Clinical Microbiology Reviews, 23(3), 616-687. http://doi.org/10.1128/CMR.00081-09

Department of State Health Service (DSHS). (2015). Summary Report - Relating to a Pilot Program to Require Reporting of Methicillin-resistant Staphylococcus aureus. Retrieved 9/20/2015 from DSHS website. https://www.dshs.state.tx.us/legislative/Attachment1-MRSAPilotReport.pdf 
Derde, L. P., Cooper, B. S., Goossens, H., Malhotra-Kumar, S., Willems, R. J., Gniadkowski, M., . . Annane, D. (2014). Interventions to reduce colonisation and transmission of antimicrobial-resistant bacteria in intensive care units: an interrupted time series study and cluster randomised trial. The Lancet Infectious Diseases, 14(1), 31-39.

Duerink, D. O., Farida, H., Nagelkerke, N. J. D., Wahyono, H., Keuter, M., Lestari, E. S., ... \& Van den Broek, P. J. (2006). Preventing nosocomial infections: improving compliance with standard precautions in an Indonesian teaching hospital. Journal of Hospital Infection, 64(1), 36-43

Eseonu, K. C., Middleton, S. D., \& Eseonu, C. C. (2011). A retrospective study of risk factors for poor outcomes in methicillin-resistant Staphylococcus aureus (MRSA) infection in surgical patients. $J$ Orthop Surg Res, 6(1), 25.

Flodgren, G., Pomey, M.-P., Taber, S. A., \& Eccles, M. P. (2011). Effectiveness of external inspection of compliance with standards in improving healthcare organization behavior, healthcare professional behavior or patient outcomes. The Cochrane Database of Systematic Reviews, (11), CD008992. http://doi.org/10.1002/14651858.CD008992.pub2

Golding, G. R., Quinn, B., Bergstrom, K., Stockdale, D., Woods, S., Nsungu, M., McDonald, R. (2012). Community-based educational intervention to limit the dissemination of community-associated methicillin-resistant Staphylococcus aureus in Northern Saskatchewan, Canada. BMC Public Health, 12(1), 15.

Goto, M., \& Al-Hasan, M. (2013). Overall burden of bloodstream infection and nosocomial bloodstream infection in north america and europe. Clinical Microbiology and Infection, 19(6), 501-509.

Gould DJ, Moralejo D, Drey N, Chudleigh JH. Interventions to improve hand hygiene compliance in patient care. Cochrane Database of Systematic Reviews 2010, Issue 9. Art. No.: CD005186. DOI: 10.1002/14651858.CD005186.pub3.

Gould, I. M. (2013). Controlling hospital MRSA. Journal of Global Antimicrobial Resistance, 1(1), 43-45. Harbarth, S., Hawkey, P. M., Tenover, F., Stefani, S., Pantosti, A., \& Struelens, M. J. (2011). Update on screening and clinical diagnosis of methicillin-resistant staphylococcus aureus (MRSA). International Journal of Antimicrobial Agents, 37(2), 110-117. doi:http://dx.doi.org/10.1016/i.ijantimicag.2010.10.022

Harris, A. (2015). Patient information: Methicillin-resistant staphylococcus aureus (MRSA) (beyond the basics) (D. Sexton \& E. Baron, Eds.). Retrieved September 15, 2015, from http://www.uptodate.com/contents/methicillin-resistant-staphylococcus-aureus-mrsa-beyondthe-basics 
Hefzy, E. M., Wegdan, A. A., \& Wahed, W. Y. A. (2015). Hospital outpatient clinics as a potential hazard for healthcare associated infections. Journal of infection and public health.

Henderson, D. M., Staiger, T. O., Peterson, G. N., Sinanan, M. N., Angiulo, C. L., Makarewicz, V. A., . . . Whimbey, E. E. (2012). A collaborative, systems-level approach to eliminating healthcareassociated MRSA, central-line-associated bloodstream infections, ventilator-associated pneumonia, and respiratory virus infections. J Healthc Qual, 34(5), 39-47; quiz 48-39. doi: 10.1111/j.19451474.2012.00213.x

Hughes, C., Smith, M., \& Tunney, M. (2008). Infection control strategies for preventing the transmission of methicillin-resistant Staphylococcus aureus (MRSA) in nursing homes for older people. The Cochrane Library.

Hughes, C., Tunney, M., \& Bradley, M. C. (2013). Infection control strategies for preventing the transmission of methicillin-resistant Staphylococcus aureus (MRSA) in nursing homes for older people. The Cochrane Library.

Jafarzadeh, S., Sohrab-Navi, Z., Bagheri-Asl, M., Naghavi-Behzad, M., Barband, S., Akhi, M., Piri, R. (2014). Staphylococcus aureus: Resistance pattern and risk factors. Journal of Analytical Research in Clinical Medicine, 3(1)

Jenkins, T. C., Stella, S. A., Cervantes, L., Knepper, B. C., Sabel, A. L., Price, C. S., . . Burman, W. J. (2013). Targets for antibiotic and healthcare resource stewardship in inpatient community-acquired pneumonia: a comparison of management practices with National Guideline Recommendations. Infection, 41(1), 135-144.

Liu C, Bayer A, Cosgrove SE, Daum RS,Fridkin SK, Gorwitz RJ \& Chambers HR (2011) Clinical practice guidelines by the infectious diseases society of America for the treatment of methicillin-resistant staphylococcus aureus infections in adults and children. Clinical Infectious Diseases 52(3), e1855.Doi:10.1093/cid/ciq146.

Luangasanatip, N., Hongsuwan, M., Limmathurotsakul, D., Lubell, Y., Lee, A. S., Harbarth, S., ... \& Cooper, B. S. (2015). Comparative efficacy of interventions to promote hand hygiene in hospital: systematic review and network meta-analysis

Lynn, M. R., \& Redman, R. W. (2005). Faces of the nursing shortage: influences on staff nurses' intentions to leave their positions or nursing. Journal of Nursing Administration, 35(5), 264-270.

Magill, S. S., Edwards, J. R., Bamberg, W., Beldavs, Z. G., Dumyati, G., Kainer, M. A., Nadle, J. (2014). Multistate point-prevalence survey of healthcare-associated infections. New England Journal of Medicine, 370(13), 1198-1208. 
Mestre, G., Berbel, C., Tortajada, P., Alarcia, M., Coca, R., Gallemi, G., . . Rodriguez-Bano, J. (2012). "The 3/3 strategy": a successful multifaceted hospital wide hand hygiene intervention based on WHO and continuous quality improvement methodology. PLoS One, 7(10), e47200. doi: 10.1371/journal.pone.0047200

Nelson, Kenrad E., and Williams, Carolyn. Infectious Disease Epidemiology (3rd Edition). Sudbury, MA, USA: Jones \& Bartlett Learning, 2013. ProQuest ebrary. Web. 10 September 2015

Prochaska, J. O., \& DiClemente, C. C. (1982). Transtheoretical therapy: Toward a more integrative model of change. Psychotherapy: Theory, Research \& Practice, 19(3), 276.

Reilly, J. S., Stewart, S., Christie, P., Allardice, G. M., Stari, T., Matheson, A., Williams, C. (2012). Universal screening for meticillin-resistant Staphylococcus aureus in acute care: risk factors and outcome from a multicentre study. Journal of Hospital Infection, 80(1), 31-35. doi: http://dx.doi.org/10.1016/j.jhin.2011.09.008

Rupp, M. E., Fitzgerald, T., Puumala, S., Anderson, J. R., Craig, R., Iwen, P. C., \& Smith, V. (2008). Prospective, controlled, cross-over trial of alcohol-based hand gel in critical care units. Infection Control, 29(01), 8-15.

Ryan, P. (2009). Integrated theory of health behavior change: background and intervention development. Clinical nurse specialist CNS, 23(3), 161.

Saint, S., Krein, S. L., \& Stock, R. W. (2014). Preventing Hospital Infections: Real-world Problems, Realistic Solutions: Oxford University Press.

Sedgwick, P. (2012). The Hawthorne effect. BMJ, 344.

Skov, R., Christiansen, K., Dancer, S. J., Daum, R. S., Dryden, M., Huang, Y.-C., \& Lowy, F. D. (2012). Update on the prevention and control of community-acquired methicillin-resistant Staphylococcus aureus (CA-MRSA). International journal of antimicrobial agents, 39(3), 193-200.

Stone, S. P., Cooper, B. S., Kibbler, C. C., Cookson, B. D., Roberts, J. A., Medley, G. F., ... \& Davey, P. G. (2007). The ORION statement: guidelines for transparent reporting of outbreak reports and intervention studies of nosocomial infection. The Lancet infectious diseases, 7(4), 282-288.

Tai-Seale, Thomas. (2014). Theories and Practice: Social \& Behavioral Health. Healthact. pp. 79, and 340. Talbot, T. R., Johnson, J. G., Fergus, C., Domenico, J. H., Schaffner, W., Daniels, T. L., ... \& Hickson, G. B. (2013). Sustained improvement in hand hygiene adherence: utilizing shared accountability and financial incentives.Infection Control, 34(11), 1129-1136. 
Velez, R. P., Becker, K. L., Davidson, P., \& Sloand, E. (2015). A quality improvement intervention to address provider behavior as it relates to utilization of CA-MRSA guidelines. Journal of clinical nursing, 24(3-4), 556-562.

Vinyard, J. (2015). Annual Report on Health Care Associated Infections (2014). Retrieved from Texas $\begin{array}{lllll}\text { Department } & \text { Health } & \text { State }\end{array}$ http://www.dshs.state.tx.us/WorkArea/linkit.aspx?LinkIdentifier=id\&ItemID=8590001389

Welsh, C., Flanagan, M., Hoke, S., Doebbeling, B., \& Herwaldt, L. (2012). Agency for healthcare research and quality hospital-acquired infections collaborative. reducing health care-associated infections (HAls): Lessons learned from a national collaborative of regional HAl programs. Am J Infect Control, 40(1), 29-34.

Whitby, M., McLaws, M. L., Slater, K., Tong, E., \& Johnson, B. (2008). Three successful interventions in health care workers that improve compliance with hand hygiene: is sustained replication possible? American journal of infection control, 36(5), 349-355

Wisplinghoff, H., Bischoff, T., Tallent, S. M., Seifert, H., Wenzel, R. P., \& Edmond, M. B. (2004). Nosocomial bloodstream infections in US hospitals: analysis of 24,179 cases from a prospective nationwide surveillance study.Clinical Infectious Diseases, 39(3), 309-317.

Wooten, D. A., \& Winston, L. G. (2013). Risk factors for methicillin-resistant Staphylococcus aureus in patients with community-onset and hospital-onset pneumonia. Respiratory Medicine, 107(8), 12661270. doi: http://dx.doi.org/10.1016/j.rmed.2013.05.006

Zacharioudakis, I. M., Zervou, F. N., Ziakas, P. D., \& Mylonakis, E. (2014). Meta-analysis of methicillinresistant staphylococcus aureus colonization and risk of infection in dialysis patients. Journal of the American Society of Nephrology: JASN, 25(9), 2131-2141. doi:10.1681/ASN.2013091028 [doi]

Zimlichman, E., Henderson, D., Tamir, O., Franz, C., Song, P., Yamin, C. K., . . Bates, D. W. (2013). Health care-associated infections: A meta-analysis of costs and financial impact on the US health care system. JAMA Internal Medicine, 173(22), 2039-2046. 